\section{Views on information technology during COVID 19}

\author{
${ }^{1}$ Darren Dookeeram, ${ }^{2}$ Ian Sammy, ${ }^{1}$ Kareema Ali \\ ${ }^{1}$ Accident and Emergency Department, Sangre Grande \\ Hospital, Eastern Regional Health Authority, Trinidad \\ ${ }^{2}$ Accident and Emergency Department, Scarborough \\ General Hospital, Trinidad and Tobago \\ ${ }^{3}$ Internal Medicine Department, Sangre Grande Hospital, \\ Eastern Regional Health Authority, Trinidad
}

\section{Corresponding author:}

Dr. Darren Dookeeram

Accident and Emergency Department

Sangre Grande Hospital

Eastern Regional Health Authority

Trinidad and Tobago

Email:dkdookeeram@gmail.com

DOI: $10.48107 / C M J .2020 .12 .006$

\section{Copyright:}

\section{(c) (i)}

This is an open access article under the terms of the Creative Commons Attribution License which permits use, distribution and reproduction in any medium, provided the original work is properly cited.
In April of 2020, the International Telecommunication Union and World Health Organization released a position statement entitled "Unleashing information technology to defeat COVID-19". ${ }^{1}$ The statement consistently intonates the positive aspects of technology solutions to key areas of the challenge that the world faces with the pandemic with little noted of the technical and bioethical dilemmas that technology may create.

The crippling nature of the SARS-CoV-2 virus results from its level of transmissibility between human hosts and it's powerful pathogenicity with a documented case fatality rate of approximately $3 \%{ }^{2,3}$ While other viruses have exerted similar pressures on healthcare systems in the past, the global surge associated with this pandemic has repeatedly overwhelmed hospital capacities and caused increasing levels of unexpected death and human suffering. ${ }^{4}$ While scientists attempt to unscramble the mysteries of the disease to decrease the viral pathogenicity, the world must innovate methods to decrease the transmissibility.

The Center for Disease Control (CDC) has documented general precautions (social distancing, masks and handwashing) and public health measures (case investigation and contact tracing) that should be followed to decrease transmissibility. ${ }^{5}$ From even an anecdotal perspective, the task of contact tracing in a small country such as Trinidad and Tobago with a population of 1.3 million has been challenging because of inefficiency, lack of population cooperation and high levels of human mobility. It therefore stands to reason that the use of contact tracing innovations, though disruptive, would be most impactful. It should also be noted that technological solutions have been used to assist in encouraging social distancing in health systems through the more accessible forms of telemedicine and improving sanitation. ${ }^{6,7}$

The bioethical debate regarding the use of these disruptive innovations is the classic matchup of the principle of beneficence as evidenced by the usefulness of the tools above weighted against the potential for violation of autonomy. The privacy risk is also well noted in contact tracing applications where third parties may gain access to confidential information. The personal and economic implications of this are far reaching if there is 
social stigma attached to the disease in their community. ${ }^{8}$ Similar to most bioethical debates, there is no clear answer to this question since it enters the realm of instrumental harm of some individuals by applying Kantian utilitarianism. But ultimately in this dilemma, by applying the principle of the greater good, the value of implementing technology can be seen as pivotal. Furthermore, the concerns can be softened with the implementation of appropriate safety measures to protect the population from real or perceived exploitation. ${ }^{9}$ The protection of health information systems has also been well described through standardized measures such as making information available only when appropriate, making health systems accountable for data use, acknowledging information perimeters and abiding to the limitations, controlling and protecting access and finally comprehensive control of access. ${ }^{10}$ It is therefore imperative that-significant oversight is applied while the technology is utilized. Of note as well is that as the disease transmission is brought under control, the technology should similarly be scaled down with a clear aim of allowing the global population to regain its full autonomy.

Information Technology scholars have cited several ways in which innovations have minimized the impact of COVID -19 including telemedicine, cashless payments, artificial intelligence (AI), modern networking, service robots and 3D printing of medical supplies. ${ }^{11}$ While some of these measures have been possible in developed countries, it would be inconceivable that lower and middle income countries would have existing and excess income to spend on AI and upscaling 3D printing. Indeed, upfront costs is a challenge for even some communities in developed countries where disposable incomes are low and families struggle to obtain appropriate hardware and software to facilitate online learning and access to social services. ${ }^{12}$

In conclusion, technology can be seen as a double edged sword in the fight against COVID-19 but the world must leverage the positive aspects while remaining cognizant of the potential threats.

\section{REFERENCES}

1. World Health Organization, 2020. WHO Statement: Unleashing information technology to defeat COVID19. [Online]

Available at: https://www.who.int/news/item/20-042020-itu-who-joint-statement-unleashing-information -technology-to-defeat-covid-19

[Accessed 31 October 2020].

2. Han, Y. \& Yang, H., 2020. The transmission and diagnosis of 2019 novel coronavirus infection disease (COVID-19): A Chinese perspective. J Med Virol, 6 (92), pp. 639-644.

3. Johns Hopkins University, 2020. Mortality Analyses. [Online]

Available at: https://coronavirus.jhu.edu/data/ mortality

[Accessed 31 October 2020].

4. Joseph, A., 2020. 'At a breaking point': New surge of COVID-19 cases has states, hospitals scrambling, yet again. [Online]

Available at: https://www.statnews.com/2020/10/20/ at-a-breaking-point-new-surge-of-covid-19-cases-has -states-hospitals-scrambling-yet-again/

[Accessed 31 October 2020].

5. CDC, 2020. Strategies to reduce COVID-19 spread. [Online]

Available at: https://www.cdc.gov/coronavirus/2019ncov/php/contact-tracing/strategies-to-reducespread.html

[Accessed 31 October 2020].

6. Iyengar, K., Upadhayaya, G., Vaishya, R. \& Jain, V., 2020. COVID-19 and applications of smartphones technology in the current pandemic. Diabetes Metab Syndr, 14(5), pp. 733-737.

7. Wang, J. et al., 2020. Disinfection technology of hospital wastes and wastewater: Suggestions for disinfection strategy during coronavirus Disease 2019 (COVID-19) pandemic in CHina. Environ Pollut, Volume 262.

8. Dobov, A., 2020. The value and ethics of using technology to contain the COVID-19 epidemic. [Online]

Available at: http://www.bioethics.net/2020/04/thevalue-and-ethics-of-using-technology-to-contain-the- 
covid-19-epidemic/

[Accessed 31 October 2020].

9. Shermer, M., 2018. Scientific American. [Online]

Available at: https://www.scientificamerican.com/ article/does-the-philosophy-of-the-greatest-good-forthe-greatest-number-have-any-merit/ [Accessed 31 October 2020].

10. National Research Council (US) Committee on Maintaining Privacy and Security in Health Care Applications of the National Information Infrastructure, 1997. For the record protecting electronic health information. [Online]

Available at: https://www.ncbi.nlm.nih.gov/books/ NBK233433/

[Accessed 31 October 2020].

11. Matthews, K., 2020. 6 ways technology is minimizing the impact of COVID-19. [Online]

Available at: https://datafloq.com/read/6-waystechnology-is-minimizing-impact-covid-19/8200 [Accessed 31 October 2020].

12. Seah, M., 2020. COVID-19: Exposing digital poverty in a pandemic. Int J Surg, Volume 79, pp. 127-128. 